\title{
The Coverage of the Nuclear Risk in Europe: Which Alternative?*
}

\author{
Michael G. Faure ${ }^{\mathrm{a}, \mathrm{b}}$ and Karine Fiore ${ }^{\mathrm{c}}$ \\ ${ }^{a}$ Metro - Maastricht University, P.O. Box 616, Maastricht 6200 MD, the Netherlands. \\ ${ }^{\mathrm{b}}$ Rotterdam Institute of Law and Economics, Erasmus University Rotterdam, Burgemeester Oudlaan 50, \\ 3000 R Rotterdam, the Netherlands. \\ E-mail: Michael.Faure@FACBURFDR.unimaas.nl \\ ${ }^{\mathrm{c}}$ Centre d'Analyse Economique - UPCAM - FEA, 3, avenue Robert Schuman, Aix-en-Provence cedex \\ 01 13628, France. \\ E-mail: karine.fiore@univ-cezanne.fr
}

The coverage of catastrophic risks, and in particular of industrial and technological risks, raises multiple questions. As nuclear risk is considered to be a special risk, its coverage is not provided in a traditional way. One of the problems in coverage of the nuclear risk is that operators today still to a large extent rely upon insurers. However, nuclear insurance is provided through national pools that operate on a non-competitive basis. These pools are costly for operators and the damage covered remains insufficient. Given their dissatisfaction with these insurance pools, many nuclear operators are now looking for alternatives. Relying on the previous work of Faure and Skogh, the goal of this paper is to examine whether a risk-sharing by nuclear operators could constitute a serious alternative for the current coverage system. In order to examine this alternative we will place it in a concrete context of nuclear operators in Europe. Moreover, we do not merely want to sketch the theoretical possibilities of a risk-sharing by operators (as this has been done before in the literature). We will in addition also examine the financial consequences for nuclear operators in Europe of such a risk-sharing agreement. The Geneva Papers (2008) 33, 288-322. doi:10.1057/gpp.2008.7

Keywords: nuclear risk; risk coverage; OECD liability conventions; risk-sharing Jel classification: Q48; Q58

\section{Introduction}

The coverage of catastrophic risks, and in particular of industrial and technological risks, raises a number of issues. For instance, how to guarantee a sufficient compensatory capacity for the victims at a sustainable cost in the event of an accident? Through which mechanisms must the potential injurer fully internalize the risk costs generated by his activity? And which legal regime may provide him with the necessary incentives to prevent accidents? The coverage of such risks is complex in

\footnotetext{
* We are grateful to the participants in the 12th Joint Seminar of the European Association of Law and Economics and The Geneva Association (Lecce, 15-16 June 2007), to two anonymous referees, and to Professor Pierre Garello (CAE, UPCAM, Aix-en-Provence), Axel Pierru (IFP, Paris) and Professor Göran Skogh (Linköping University) for their useful comments on an earlier version of this paper.
} 
several respects and requires particular attention. Nuclear risk pertains to the category of potentially catastrophic risks and has particular characteristics which distinguish it from traditional risks. Nuclear risk refers to incidents or accidents likely to occur in nuclear installations (plants, storage depots, waste treatment factories, etc.). This risk can be of endogenous origin (leakage of ionizing rays, radioactive heat emission, reactor core melt, etc.) or of exogenous origin (human error, landslide, storm, earthquake, terrorist attack, etc.). Moreover, a nuclear accident can have very serious and long-term consequences for the environment and human health. It can also cause serious economic disturbances which lead to considerable difficulties in damage assessment. As far as the environment is concerned, a nuclear accident might cause significant natural and sanitary damage. In human terms, it could result not only in immediate death but also malformations and diseases, the first symptoms of which may only appear several decades after the accident. In addition, nuclear risk is largely irreversible, and this irreversibility is made worse by the fact that the risk is partially unpredictable ex ante. Therefore, nuclear operators and their insurers claim not to possess the necessary tools to estimate and quantify it with precision. Thus, it seems to be difficult for them to determine its probability of occurrence with a sufficient degree of accuracy. This is especially true since a nuclear accident is a low probability event and it may be difficult to delineate costs attributable to the operator. In summary, reliable data on the probability of a nuclear accident and the corresponding damage, as well as the capacity to evaluate the potential consequences, are often lacking.

As nuclear risk is considered to be an exceptional risk, its coverage is not provided in a traditional way. Under different international conventions, nuclear operators are legally obliged to cover their civil liability in the event of an accident on one of their installations. As far as Europe is concerned, this obligation forms part of an international regime created under the auspices of the Nuclear Energy Agency (NEA), a specialized agency of the OECD, through two international conventions: the Paris (1960) and Brussels (1963) Conventions. Under these Conventions, nuclear operators' civil liability is limited, ${ }^{1}$ and such operators are required to take out and maintain insurance or other financial security to cover it. A second layer of compensation (in addition to the liability of licensees) is provided by the State in which the nuclear installation on which the accident occurs is located. A third layer is provided by all of the contracting States.

This structure of the compensation regime for nuclear accidents has been criticized for a number of reasons: first, the low financial cap may provide the nuclear operator with insufficient incentives for prevention; secondly, the financial cap (combined with the public compensation scheme) is viewed by many as a subsidy to the nuclear power industry since not all costs are internalized; ${ }^{2}$ and thirdly, notwithstanding the public compensation scheme, victims might never be fully compensated in the event of a

\footnotetext{
${ }^{1}$ This liability cap was initially (in 1960) fixed at 15 million SDR (about $€ 17$ million) and has since been increased several times. The last increase was introduced by the 2004 Protocols amending the Paris and Brussels Conventions, which fixed the cap at $€ 700$ million. These Protocols have not yet entered into force, though they are expected to in early 2008 . Henceforth, we will use "m€" for "million€".

2 Dubin and Rothwell (1990); Heyes and Liston-Heyes (1998, 2000); Fiore (2006).
} 
major nuclear accident. ${ }^{3}$ The relevant international conventions have recently been changed in order to (substantially) increase the extent of liability as well as the amounts available under the public compensation scheme, but the same criticisms still apply.

It was previously argued in the literature that substantially higher amounts of compensation could be provided through a pooling by nuclear operators. ${ }^{4}$ Such a pooling system still does not exist for the nuclear risk and moreover, its practical possibilities have never been worked out in detail. Indeed, one of the problems concerning coverage of the nuclear risk is that operators still rely on insurance to a large extent. However, nuclear insurance is provided through national pools which operate on a non-competitive basis and therefore appear to charge excessively high premiums. Given their dissatisfaction with these (national) insurance pools, many nuclear operators have now developed alternatives. Some (such as the French nuclear operator EDF) secure financing by means of their own reserves, while others participate in so-called "captives" established by nuclear operators. However, all of these alternatives continue to function within the current context of a (still relatively low) financial cap on the liability of the operator. The question therefore arises as to whether a pooling system based on risk-sharing by operators could generate substantially higher levels of coverage, even if the liability of the licensee of a nuclear operator were to be made unlimited (as has been suggested in earlier literature).

The goal of our paper is therefore to determine whether this risk-sharing by nuclear operators could constitute a genuine alternative to the current coverage system. We will examine this alternative with reference to the concrete example of nuclear operators in Europe. We do not merely intend to sketch the theoretical possibilities of risk-sharing by operators (as this has already been done in the literature) but also to examine the financial consequences of such a risk-sharing agreement for nuclear operators in Europe.

Given this purpose, our paper is structured as follows: after a brief introduction, we follow with a sketch of the current coverage of the nuclear risk in Europe. We demonstrate the way in which the insurance pools function at present (referring to the example of France) and identify a few costs and inefficiencies of the insurance scheme. In the next section we then elaborate the potential alternatives and show that where insurance (as a result of market failure due to market dominance) does not provide an optimal result, various alternatives can be considered and indeed have been applied in practice. In the penultimate section we present our alternative, namely a risk-sharing agreement between European operators, not only by elaborating the relevant principles, but also by providing some methods of calculation for calculating the precise contribution of each operator. Finally, the last section offers the conclusions.

\footnotetext{
${ }^{3}$ Faure and Van den Bergh (1990); Trebilcock and Winter (1997). A related difficulty to evaluate the cost of an accident (and its probability) is that the share of health damage attributable to the nuclear accident is often difficult to measure given uncertainty over causation in case of ionizing radiation. For further details, see Spadaro and Rabl (1998) and Schieber and Schneider (2002).

${ }^{4}$ Faure and Skogh (1992).
} 


\section{The current coverage of the nuclear risk in Europe}

\section{The structure of the market}

The supply of the insurance market: the nuclear insurance pools and mutuals

Faced with the catastrophic scale of the consequences of a nuclear accident and the threat posed by the potential financial losses to their solvency, insurers initially opted to exclude the nuclear risk from their classic insurance policies altogether. This decision was motivated by the fact that no individual insurer possessed the necessary resources to manage the risk and therefore to contain their financial commitments. In other words, the nuclear risk possessed such extraordinary characteristics that the traditional insurance market could not cover it. The risk was viewed as uninsurable mainly due to the low probability of a nuclear accident.

The exclusion of the nuclear risk from private insurance was then supplemented by several formal exclusion clauses implemented at the international level. The most important of these was the 1975/1994 NMA clause (by the Non-Marine Association of the London-based insurer Lloyd's). This clause, entitled Nuclear Energy Risks Exclusion Clause (Reinsurance), is still enforced today in respect of property and liability insurance contracts as well as their corresponding reinsurance treaties.

These different exclusion clauses combined with the general reluctance of private insurers to cover the nuclear risk led them to adopt an original insurance solution in the 1950s: they gathered their financial assets in specialized pools. In Europe, these pools were created in each of the main insurance markets, combining their financial means through reinsurance. The same type of insurance solution was adopted first in the U.S. and later in the rest of the world. The gathering of financial assets within a pool is often seen as a way of increasing the insurance capacity by providing higher amounts for the coverage of a particular risk. ${ }^{5}$ It consists of an ex ante contractual agreement between different insurers (and also sometimes between insurers and reinsurers), made when the risk is considered to be uninsurable on the private market and when only the pooling of capacities guarantees a certain insurance supply. Such agreement is based on the fundamental principles of mutuality and solidarity between pool members. The financial means are pooled and losses and benefits shared among all participants. At present there exist 28 nuclear insurance and reinsurance pools in the world, of which 17 are located in Europe.

Given that these pools are defined as the gathering of insurers within the same organization, the nuclear insurance pools are very concentrated. This specific market structure is accentuated by the fact that the insurers and reinsurers of the pools are specialized exclusively in the coverage of the nuclear risk. ${ }^{6}$ This specialization has several advantages. Above all, it allows the members of each pool to share their knowledge and information about the risk and therefore to benefit from the positive externalities derived from this. ${ }^{7}$ These factors allow them to better measure the risk and, in turn, to determine the insurance premium they require from the nuclear

\footnotetext{
${ }^{5}$ Faure and Hartlief (2003); Faure (2004).

${ }^{6}$ Dow (1985); Reitsma (1992).

${ }^{7}$ Faure and Van den Bergh (1995).
} 
operators with a greater degree of accuracy. Of course, these advantages are conditioned by the operators' and experts' capability to predict the risk and its consequences in detail.

However, the nuclear insurance pools are created solely on a national basis. In other words, each country has its own pool and the various pools do not compete with one another. Most of these pools cover not only the nuclear operators' liability but also the property damage to their installations. As far as their capacity is concerned, at the beginning of each year the insurers of the pool determine the amount they are willing to pay for each nuclear installation insured. The total sum of the insurers' contributions constitutes the capacity of the national pool. Thus, if nuclear operators wish to meet their coverage obligation by way of insurance they have no choice but to resort to their national insurance pool. ${ }^{8}$

In light of the revision of the Paris and Brussels Conventions, as well as the necessity to increase the capacity of the nuclear insurance market, mutuals have been created in Europe to supplement the pools, inspired by U.S. practice. Belgium was the first to take this initiative by creating the European mutuals EMANI ${ }^{9}$ (European Mutual Association for Nuclear Insurance) and ELINI ${ }^{10}$ (European Liability Insurance for the Nuclear Industry). They consist in mutual insurance associations, also known as captives, providing nuclear operators and other industry actors with coverage of the risks connected with their activities. In contrast to pools, they are organized at the international level. The capacity of these mutuals is totally independent of the capacity of the different nuclear insurance pools. They are financed by the members' contributions, determined according to their profile of risk. For example, in 2005, EMANI received $€ 25$ million in contributions from its members and ELINI received $€ 1$ million. ${ }^{11}$ Their main advantages are: a supplement or a substitution capacity for the risks of property damage, trading losses and nuclear civil liability; the possibility of reducing contributions in time, of distributing the benefits to their members and of pooling expertise on prevention and engineering; and the creation of a forum for exchanges and information in the nuclear insurance field. ${ }^{12}$ However, these mutuals still remain bound to the national pools in the sense that, in the event of an accident, they are generally required to follow the recommendations made by the experts nominated by the pools.

\footnotetext{
${ }^{8}$ In the case of reinsurance only, it is sometimes possible that the pools intervene at the international level. For example, the Belgian insurance companies participating in the Belgian pool SYBAN (Syndicat Belge pour l'Assurance Nucléaire) compensated a share of the damage caused by the Three Miles Island nuclear accident in the U.S. in 1979 (Faure (2006)). However, this possibility applies only to the insurers and not the operators, who remain bound to their national pools.

${ }^{9}$ EMANI was established in Brussels by a Royal Ordinance on 20 October 1978. It covers civil liabilities, nuclear damage and the disruption of its members' activities. It currently includes 43 international operators in 13 different countries. See www.emani.be.

${ }^{10}$ ELINI was also established in Brussels under Belgian legislation, and was authorized by way of a decision of the Management Comity of the CBFA (Commission bancaire, financière et des assurances) of 6 November 2003. It is specialized in the coverage of its members' civil liability. At present it comprises 24 members in nine different European countries. See www.elini.net.

${ }^{11}$ EMANI (2005); ELINI (2005).

12 Vilnet (2004).
} 
With the Price-Anderson Act, the U.S. built a system based on similar principles. The concentrated and specialized insurance market (around the American Nuclear Insurers (ANI) pool) is supplemented by two specialized mutuals: NEIL and ONEIL. NEIL (Nuclear Electric Insurance Limited) was created by nuclear operators in 1980 in response to the Three Miles Island accident. It too covers its members' civil liability but is mainly specialized in property insurance. ONEIL (Overseas NEIL) is the Irish extension of NEIL, created in 1999 in partnership with the ACE (ACE Bermuda Insurance Limited) for the European nuclear operators. NEIL is in direct competition with ANI, which it reinsures up to 45 per cent. The current total capacity of NEIL (property and liability) is 3 billion U.S. dollars.

So how do these different actors interact with each other on the nuclear insurance market? Let us take the example of the French market to explain this.

\section{The nuclear insurance market in France}

The first insurance contracts stipulated by the operators Commissariat à l'énergie atomique (research) and Electricité de France (EDF) (production) were signed in 1957. France is party to the Paris and Brussels Conventions and therefore the French nuclear operators' civil liability is governed by them. Their liability is financially limited and the insurance of their risks compulsory. In that respect, the French Nuclear Act (1968/1990) caps their liability at €91 million per accident. ${ }^{13}$ EDF, the nuclear production monopoly in France (operating 58 reactors), meets its insurance obligation in two ways. For the first two thirds (up to $€ 60$ million), it guarantees its liability through its own financial reserves, and for the last third (the remaining $€ 31$ million) it resorts to insurance (EDF (Electricite de France), 2006). ${ }^{14}$ This is "excess of loss" insurance. Therefore, strictly speaking, only $€ 31$ million are insured. For this last third, EDF has taken out insurance policies with the French insurance pool Assuratome $^{15}$ and ELINI. These policies cover its liability in the event of an accident on one of its installations as well as during transportation. Assuratome covers all nuclear installations in France (EDF's nuclear power stations, waste treatment factories, medical and other industrial nuclear installations, as well as waste transportation and dismantling). In 2003, the total capacity of Assuratome amounted to $€ 365$ million, of which $€ 114$ million was for the coverage of the civil liability, ${ }^{16}$ and $€ 251$ million was for the first-party insurance (for damage to the nuclear installation).

13 This Act implements the Paris and Brussels Conventions. As stated in Faure and Skogh (1992), the cap will be increased to $€ 700$ million when the 2004 Protocols are implemented in the States Parties to the Paris and Brussels Conventions.

14 Carrez (2003).

${ }^{15}$ Assuratome is a reinsurance pool comprising 86 insurance and reinsurance companies (including AGF (Assurance Générale de France) and AXA Corporate Solution) which was created specially for this purpose (Carrez (2003); De Loustal (2003)). The original French nuclear pool was the PFARA (Pool Français d'Assurance des Risques Atomiques) set up as an association in 1957. The PFARA was then transformed into an Economic Interest Grouping (EIG) in 1969 and finally became Assuratome in 1995. Assuratome is subject to strict requirements in terms of fiscal transparency and regulatory control by the CCA (Commission de Contrôle des Assurances) and the Insurance Code (De Loustal (2003)).

${ }^{16}$ De Loustal (2003); Betbèze and Bentoglio (2005). 
Two observations follow from this brief account. On the one hand, we can observe that the aforementioned capacity is quite substantial, but much lower than in the case of other insurance solutions such as the U.S. mutual NEIL. On the other hand, the capacity exclusively devoted to the coverage of the operators' liability is barely higher than the current liability limit ( $€ 114$ million $>€ 91$ million). ${ }^{17}$ The question is therefore to what extent Assuratome will be able to meet the new coverage requirements ( $€ 700$ million) by 2008 , as fixed by the recent legislative amendments of the 2004 Protocols. This question is all the more important given that, as we will demonstrate, the insurance provided through Assuratome, like the other nuclear insurance pools, is very costly.

\section{Costs and inefficiencies}

The creation of national and specialized insurance pools in the 1950s, combined with the liability cap, was the solution provided by the market and the government to cover the nuclear risk and to make it insurable. However, this solution suffers from important limitations: first, the pools are non-competitive and secondly, the insurance premiums charged by the pools are excessively high.

The pools are non-competitive. Indeed, they benefit from an exemption of European competition law. This exemptive regime is laid out in Article 81(3) of the Rome Treaty, supplementing Article 81(1), which explicitly forbids groupings and agreements between firms. According to Article 81(3), in some cases agreements between firms are more desirable than competition. This is especially the case with the insurance market, which is often viewed as a particular market. Hence, this market is exempted from Article 81(1) (albeit under strict conditions) and governed by CEE no 358/2003 of 27 February $2003,{ }^{18}$ which explicitly exempts pooling arrangements from European competition law. ${ }^{19}$

However, this pooling can take the form of a cartelization of information and, as such, can create an artificial barrier to entry into the market. For this reason, this exclusion of pooling from competition law has been criticized in the literature, ${ }^{20}$ particularly as it allows insurers to behave as lobbies. ${ }^{21}$ In addition, one can question

${ }^{17}$ According to some authors (see Muller (1985)), first-party liability insurance even has priority over thirdparty liability insurance since a nuclear accident is likely to affect the installation itself before affecting the surrounding area. This combination of first-party and third-party liability insurance through the nuclear pools therefore leads to a limitation of the amount available for third-party liability insurance. It is also remarkable that, during an OECD conference in Munich in 1984, brokers argued that first-party insurance should be removed from the pools.

18 This Directive follows the previous Directive CEE no. 3932/92 of 21 December 1992, which expired on 31 March 2003. The current Directive will expire in 2010.

${ }^{19}$ Levie and Cousy (1994); Furse (2006).

${ }^{20}$ Havens and Theisen (1986); Faure and Van den Bergh (1995); Faure (2006).

${ }^{21}$ Faure and Van den Bergh (1995) showed that in the case of nuclear insurance in Belgium, the activity of lobbying operates between two monopolies on a bilateral basis: on the one hand, the insurers' pool benefits from its dominant position, charging high premiums and restricting the entry of new insurers onto the market and, on the other hand, the nuclear industry (itself also very concentrated in most of the nuclearized countries) benefits from a financial limit to its liability in the event of an accident. 
the efficiency of the nuclear pools in light of their geographic scope. While the exemptive EC Directive mentioned above is silent on this point, one can wonder whether the organization of nuclear insurance at the national level is effective. First, the current division of the market into national pools may not be suitable in light of the fact that many customers (i.e. energy suppliers) are organized in international groups. Secondly, a nuclear accident may have cross-border effects, and thereby lead to the liability of operators from different countries. Third, the organization of the pools at the national level limits the available capacity.

In summary, although the nuclear authorities contend that without these pools the nuclear risk would be uninsurable, doubts remain as to the optimality of this solution. At present, the pools suffer from inefficiency and obsolescence, which is mainly reflected in excessive costs.

Indeed, one of the main criticisms levelled at the insurance pools is that they charge excessive insurance premiums. ${ }^{22}$ This can be demonstrated using a precise example: the case of France. ${ }^{23}$

The French nuclear operator EDF currently administers 58 reactors and has adopted a system of partial insurance to cover its civil liability. Under its insurance contract, the total amount covered is $€ 31$ million per accident. For this insurance, EDF currently pays a premium of $€ 6.4$ million/year (all tax included) for all of its reactors. ${ }^{24}$ As in traditional insurance markets, the premium should include the objective value of the risk (also called the "actuarial" or "indicative" premium), the pool's loading costs (generally estimated to about 30 per cent of the objective value of the risk ${ }^{25}$ ), and a surcharge for risk aversion, taxes and the insurers' benefit. ${ }^{26}$ This can be added to the premiums actually charged by the nuclear pools. In previous research, ${ }^{27}$ we showed that EDF's indicative premium for its 58 nuclear reactors should be: $P=€ 17,980 /$ year (Appendix A). The difference between this premium and the premium currently paid by EDF is huge. In fact, this current premium is 355 times higher. Earlier, we examined the potential reasons for this large gap. Although we were unable to give a clear and distinct answer, we concluded that one possibility is that insurers impose a considerable surcharge because of their risk aversion, while another explanation might be that the internal costs or benefits of the nuclear pools are quite high. In our view, the explanation stems from a combination of different factors linked to the monopolistic structure of the market and to the uncertainty surrounding the risk. There may, however, be other reasons (beyond the scope of this paper) which serve to explain why the insurance industry has charged excessively high

${ }^{22}$ Faure (1995); Faure and Van den Bergh (1995).

23 Fiore and Faure (2006).

${ }^{24}$ This premium does not include the insurance of the operator's liability for accidents during transportation, which is a specific form of insurance.

${ }^{25}$ See U.S. Congress Joint Committee on Atomic Energy (1974); Dubin and Rothwell (1990); Heyes and Liston-Heyes (1998, 2000).

${ }^{26}$ Kunreuther (1997); Faure and Fenn (1999); Faure and Fiore (2006).

${ }^{27}$ Faure and Fiore (2006). Given the opacity of the nuclear insurance pools, as well as commercial secrecy, one cannot obtain a detailed calculation of the premium paid by EDF. Our 2006 analysis was therefore based on the methods developed by the economic literature for calculating insurance premiums, that is, on the objective value of the risk. 
premiums. Suffice to say at this point that the evidence shows that premiums charged are higher than actuarially fair values. Although our empirical evidence was limited to the case of France, there are indications that the situation is similar in other European countries (indeed, it is difficult to see why that would not be the case).

Given these factors, particularly the high costs involved in the operation of the pools, we can again question whether the nuclear insurance pools will be able to increase their capacity in order to allow the European operators to meet their new financial cap (of $€ 700$ million) imposed by the 2004 Protocols. Moreover, these high costs are not the only problem with the pools. The compensation amounts generated through them in Europe are not very substantial either. Even though the liability was substantially increased in 2004 (up to $€ 700$ million), these amounts still seem to be largely insufficient to cover the costs of an average nuclear accident (which vary between $€ 10$ billion and $€ 100$ billion, depending on the different scenarios). ${ }^{28}$ At present this insufficiency is remedied (albeit only partially) through the provision of additional compensation by the State and by the signatory States. ${ }^{29}$ The total coverage (in France) currently amounts to $€ 381$ million and will amount to $€ 1,500$ million after the entry into force of the 2004 amendments. Thus, these amounts are still very low, meaning that victims might be undercompensated (depending of course on the scale of the damage). The limit on the liability of the nuclear operator may also lead to an implicit subsidy of nuclear power and therefore to a lack of internalization of nuclear costs by the operator. ${ }^{30}$ This leads us to the central question of our paper, namely whether it would be possible to find an alternative solution which generates substantially higher amounts of compensation for victims at lower cost and, in addition, results in a better internalization of the nuclear risk.

\section{Potential alternatives}

\section{Starting points}

Law and economics literature has always indicated that liability of nuclear operators should in principle be unlimited. ${ }^{31}$ Only through unlimited liability can an effective internalization of the nuclear risk be achieved. However, given the scope of the nuclear risk, it is clear that without additional institutional arrangements internalization will not follow automatically from unlimited liability, nor will there be a guarantee of full compensation for the victims. Indeed, even though the assets of nuclear operators may be substantial, it is still very likely that the damage caused by a nuclear accident will be considerably higher than the available assets of the operator. Hence, unlimited liability needs to be combined with alternative compensation mechanisms that may at the European level guarantee compensation of at least the costs of an average nuclear accident.

\footnotetext{
${ }^{28}$ Schieber and Schneider (2002); Spadaro and Rabl (1998).

${ }^{29}$ The damages financed by the States currently amount to $€ 290$ million (in France) and will amount to $€ 1,200$ million after the implementation of the 2004 amendments.

${ }^{30}$ Faure and Fiore (2006).

${ }^{31}$ Faure and Skogh (1992).
} 
However, any compensation mechanism will still have to be based upon the calculation of a limit. In this respect, inspiration can be drawn from the American Price-Anderson Act, which currently provides compensation of up to 10.76 billion U.S. dollars. Furthermore, this also corresponds to estimates of the cost of a major nuclear accident (in the most optimistic scenarios). In order to simplify calculations, we will assume that an amount of $€ 10$ billion should be set aside by the nuclear operators as available compensation to victims. This may not compensate all victims in all circumstances, but as a first step this would at least be satisfactory. Moreover, this amount would be substantially higher than that which is currently available under the NEA regime.

A second condition for an alternative regime is that the compensation should in principle be generated by the nuclear operators themselves. State intervention, as is still the case today in the NEA regime, should therefore be avoided. The economic rationale for that starting point is clear: State intervention runs counter to the principle of internalization of the nuclear costs by the operator.

A third condition is that any alternative should in principle be available today, or at least should realistically be expected to be implemented at the European level. The reason for this condition is that in the literature a variety of theoretically feasible alternatives have been advanced, but with many of these as yet lacking concrete application, it may not be realistic to present them as an alternative for financing the $€ 10$ billion of compensation which should be made available in case of a nuclear accident. In this respect we refer more particularly to the concept known as alternative risk transfer (ART) or securitization and the use of capital markets as an alternative for covering nuclear damage. ${ }^{32}$

Some economists, particularly Tyran and Zweifel, ${ }^{33}$ have for instance advocated the use of capital markets to provide coverage for environmental damage. They suggest that plant operators should be permitted to acquire risk-participation shares on capital markets. Investors would have the opportunity of acquiring such shares in exchange for financial assets, creating a warrant in favor of the plant of their choice. This warrant could be invoked by the agency when liability claims are presented. Since operators must have sufficient coverage, they will compete for coverage capital and, accordingly, bad risks will not be able to obtain coverage. Hence Tyran and Zweifel argue that their ERICAM ${ }^{34}$ system could correct the market failure and provide wider coverage of the nuclear risk and improved safety. The idea behind ERICAM is that the interest rate on the bonds issued reflects the accident rate and thus the operators' care. The ERICAM system certainly has advantages over the current system of limited liability and non-competing insurance pools. Furthermore, this idea of using capital markets to finance potential liabilities for environmental harm and catastrophic risks is not merely theoretical. Nowadays it is possible to buy "catastrophe bonds" inter alia on the New York Stock Exchange. However, we will not focus on these alternatives in

\footnotetext{
${ }^{32}$ For overviews of these alternatives, see for example Radetzki and Radetzki (2000) as well as Faure (2004). For securitization, see Wagner (1998).

33 Tyran and Zweifel (1993).

${ }^{34}$ ERICAM stands for Environmental Risk Internalization through Capital Markets.
} 
much detail as, according to insurers, they do not yet play a major role in Europe. ${ }^{35}$ Moreover, it is argued that these "new" financing instruments based on capital markets will never replace traditional products completely. ${ }^{36}$

In summary, none of these possible alternatives has yet been applied in Europe. ART is applied in the U.S., but not with respect to the nuclear risk. Therefore, notwithstanding the interesting suggestions in the literature, we will not examine this alternative further within the scope of this paper. Instead, we will focus on the alternatives currently available in Europe, namely insurance, reserves, as well as present our own alternative, that is, risk-sharing.

\section{Insurance}

As indicated above, insurance is widely applied to the nuclear risk. Therefore, in theory, insurance could also be used to cover the increased amount of $€ 10$ billion which in our model should be made available to compensate victims of a nuclear accident. However, as we showed in the section on costs and inefficiencies, there exist many inefficiencies and limits to the possibility of covering the nuclear risk through the insurance market. The outcome is relatively predictable. Given the monopolistic premiums charged by the nuclear insurance pools there is obviously little willingness on the part of nuclear operators to pay them. As a result, on the one hand, nuclear operators in Europe have moved to the establishment of mutual insurance schemes while, on the other, they have increasingly made use of other available methods of coverage (like the reserves set aside by EDF).

In summary, it is not difficult to predict, both from a theoretical perspective and on the basis of the experience of the nuclear insurance pools in Europe, that insurance will not be an attractive alternative to cover the $€ 10$ billion which should be made available. Relying on the current French insurance premium and on the equation in Appendix B, it can easily be calculated that the insurance costs to cover the $€ 10$ billion would be excessively high. Indeed, taking the French premium as a representative example of the situation in European countries, we obtain the following insurance premium: $P=€ 37.3$ million per reactor per year, that is, for EDF, $€ 2.1$ billion per year. This premium is considerably high, especially compared with our alternative (as we will demonstrate below). Let us now examine another alternative already used today and allowed by the international conventions, namely the use of the operators' own reserves.

\section{Reserves}

The theory behind the use of reserves is that operators would make use of available assets to cover the nuclear damage in the event of an accident. For those operators who have large assets available, using these reserves may at first sight appear extremely attractive, especially when compared to insurance. One disadvantage of insurance is

\footnotetext{
${ }^{35}$ Smith et al. (1997).

36 Zech (1998).
} 
that the premiums have to be paid to the nuclear insurance pools and, in addition, once these premiums are paid to the insurer the operator will never be able to retrieve them should no accident occur during the life span of the nuclear installation. Thus, insurance premiums are considered to be "lost money". ${ }^{37}$ Conversely, if a reserve is set aside to cover a potential accident, this amount would of course still be available to the operator if no accident occurs.

Notwithstanding the attractiveness of reserves in theory there are obvious disadvantages as well. First of all, the scale of the assets which have to be made available to cover a nuclear accident may be so high that it would be practically impossible, especially for small operators, to cover this risk through reserves. In this respect, a distinction should be drawn between the many cases in which nuclear installations remain state-owned and therefore operators can rely on the large State funds, and the other cases where the nuclear installation is private. As far as regards the latter, this substantial backup of the State may not be available, in which case making full use of their own reserves would not be a realistic option. Given the political desire to liberalize energy markets, it is likely that in the future State participation in nuclear power will diminish and more operators will be from the private sector. The likelihood that they will have large assets available which could serve as a reserve in the event of an accident is therefore not very high. To our knowledge, few operators make use of this possibility, with the exception of the French operator EDF, which is still 80 per cent state-owned.

Secondly, these reserves are called "reserves for self-insurance" 38 and are subject to very strict accounting rules. ${ }^{39}$ They form part of the operators' capital funds and do not yield any benefits to them. They are also costly. Indeed, from the operators' perspective, using their own reserves is not always the cheapest option, notwithstanding the excessive insurance premiums. The problem is that setting aside assets as a reserve leads to an immobility of capital for which a cost also has to be calculated. This cost has two components. First, it includes the expected cost of losing the whole or part of the reserves set aside in the event of an accident. Secondly, given that an operator's reserves are an element of its capital funds, there is also the cost related to the profitability required from shareholders on the firm's resources. Evaluating the cost of reserves for self-insurance (and of reserves in general) is equivalent to evaluating the cost of capital funds. In the financial literature, this cost is calculated on the basis of the CAPM (Capital Asset Pricing Model), ${ }^{40}$ and called the "profitability rate", noted as $k$. In Fiore and Faure, ${ }^{41}$ we found that for EDF $k=8.6$ per cent (low evaluation) or $k=13$ per cent (high evaluation) per year (Appendix C). Equally, we

\footnotetext{
${ }^{37}$ Pelzer (2007, p. 48).

${ }^{38}$ Even though one could criticize the use of the word "insurance". Insurance assumes risk-spreading, whereas in the case of reserves, there is only a spreading of risk over time, but not with other parties exposed to a similar risk (see Faure and Hartlief (2003, pp. 144-146)).

${ }^{39}$ These rules come from the IFRS (International Financial Reporting Standards) norms of the IASB (International Accounting Standards Board).

40 This method was developed at the end of 1950s and in the early 1960s in the works of Markowitz (1952, 1959); Treynor (1961, 1962); Sharpe (1964); and Lintner (1965).

${ }^{41}$ Fiore and Faure (2006).
} 
showed that, generally speaking, reserves are cheaper than insurance. How much would the coverage of $€ 10$ billion cost if the operators set aside such reserves for self-insurance on an individual basis? Relying on our previous work ${ }^{42}$ and on Appendix C, we obtain a cost of reserves of: $A=€ 240.8$ million (low evaluation) or $A=€ 248.1$ million (high evaluation) per year for one reactor operated. For example, for an operator which manages 15 reactors (such as British Energy), the cost of reserves would amount to $€ 241.2$ million (low evaluation) or $€ 248.4$ million (high evaluation) per year. We can observe that reserves are a more interesting option for large operators, since the annual cost of reserves decreases (in proportion) when $n$ grows. This is due to the fact that, whatever their amount, the reserves are costly because of the profitability rate $k$ (Appendix C). This rate is the same whether the reserves are high or low. As a result, the more reactors the operator has, the more it can spread its cost over a large number of installations.

In short, the cost of reserves is very high. It should be noted, however, that this calculation is based on the current levels of profitability in the energy sector, whereby EDF was taken as a benchmark. The figures may therefore vary for other operators. Still, the point remains that reserves also constitute an expensive way for operators to generate assets for compensation. Moreover, reserves do not include any element of risk-spreading (neither between operators, nor over time) and for that reason they too may be less attractive than insurance in case of risk aversion on the part of the nuclear operator.

From society's perspective, reserves as a method to cover the nuclear risk are also hazardous for the simple reason that they provide no guarantee that these assets will be made available to victims of the nuclear accident when it occurs. Assets may be available at the beginning of the operation but, due to changing business circumstances, the operator may wish to make use of part of these assets, as a result of which they may no longer be available when the accident happens. This shows that it does not suffice merely to rely on the operator's declaration that a reserve has been created; a reserve must actually be set aside in order to guarantee compensation to the victim, which is precisely what makes it very costly. Moreover, in case of insolvency and more particularly bankruptcy (which is in fact very likely after a nuclear accident) it is necessary to guarantee that the victims can still claim the reserve which has been set aside to cover the operator's liability. Thus, if reserves are also used, a statutory provision has to be drafted to ensure that victims of the nuclear accident are accorded priority over the use of these assets.

The most important reason why reserves set aside by the operator are (except in the case of the State-owned operator) not a realistic alternative to cover the entire damage is of course that the amount of the reserves would have to be so high that for most operators this would be impossible. At best, reserves may play a partial role in combination with insurance. Hence, it now becomes necessary to present the third alternative. 


\section{Risk-sharing}

Risk-sharing is conceptually very different from insurance. The two are not based on the same principles and do not have the same implications in terms of costs and functioning.

The notion of risk-sharing has often been advanced to deal with large and uncertain risks and has notably been analyzed by a number of people. ${ }^{43}$ This mechanism consists in gathering different operators subject to the same risk within a single pool. The pool is implemented by way of an ex ante agreement between the operators to jointly cover the risk. There already exist agreements between industrial operators to cover technological or environmental risks. For example, the Protection and Indemnity Clubs deal with the risk of maritime oil pollution by covering the civil liability of the world's tanker owners on a voluntary, mutual and non-profit basis.

Although a risk-sharing agreement to cover nuclear risks does not exist in Europe, there is a comparable agreement between nuclear operators in the U.S. The PriceAnderson Act, ${ }^{44}$ which has governed the civil liability regime of the U.S. nuclear operators since 1957, introduced two layers of risk. The first is the operators' liability which, since the last amendments to the Act in 2005 , amounts to $\$ 300$ million. As in the Paris and Brussels Conventions, the U.S. operators' liability is strict and has to be insured on a compulsory basis. This insurance is provided by a pool of private insurers, the ANI. As far as the second layer of risk is concerned, this is not covered by the State as in Europe, but by an agreement according to which each nuclear operator has to pay a retrospective premium of up to $\$ 100.6$ million per reactor in the event of an accident if the resources pertaining to the first layer of risk are insufficient. These contributions are based on mutual and solidary risk-sharing between operators and calculated on a pro-rata basis for the 103 U.S. nuclear reactors. They are independent from insurance and from the State. They are supported by a guarantee pledged by each operator to the Nuclear Regulatory Commission (NRC) every year, which consists of a promise of payment by the operator in the event of an accident, and has to be certified by the NRC to be valid. ${ }^{45}$ This two-tier system in the U.S. provides a total coverage capacity of $\$ 10.76$ billion, with the operators' participation alone.

This type of ex ante mutual risk-sharing between operators has many advantages over insurance. First, it does not require the same degree of information about the risk. ${ }^{46}$ Insurance requires fairly precise information about the risk (reliable statistical data, accurate evaluations as to the extent of damage, the possible scenarios and the corresponding probabilities) in order to calculate the most adequate price for the risk coverage. A problem arises, however, when the insurer faces an uncertain risk, such as the nuclear risk, for which the statistical data and the probabilities do exist but are rare

\footnotetext{
${ }^{43}$ Skogh (1999); Holm (1999); Faure and Hartlief (2003); Pelzer (2007).

${ }^{44}$ The Price-Anderson Act is a U.S. federal law that was originally enacted by Congress in 1957 as an amendment to the Atomic Energy Act in order to establish a system of financial protection for operators who may be liable for a nuclear accident or incident on one of their installations and for victims who may be injured as a result. In 1988, and more recently in 2002, the Act was renewed with amendments.

${ }^{45}$ We will come back to these guarantees in the section on financial methods below.

${ }^{46}$ Michel-Kerjan and Marcellis-Warin (2006); Wu and Skogh (2005).
} 
and, moreover, hard to estimate. Risk-sharing avoids this problem, as it is not necessary for the participants in the pool to know precisely the probabilities of the risk occurring in order to evaluate each contribution. ${ }^{47}$ They only need information about the risks generated by each member in order to differentiate between them. For this purpose, they can rely on, for example, their technological differences, their safety standards, or the size of their installations. Efficient risk differentiation is one of the most important conditions for the success of a risk-sharing pool. ${ }^{48}$

Secondly, risk-sharing has the advantage over insurance of allowing a better monitoring of the members' attitude towards the prevention of accidents. This is particularly the case when the pool members are not too numerous. Indeed, it is more difficult for the insurer to control his policyholders' behavior because, on the one hand, he might suffer from an informational asymmetry as to the risk actually generated by the entire group and, on the other, the number of participants may be large and therefore hard to monitor simultaneously. By contrast, in a risk-sharing pool, the nuclear operators are faced with the same type of risk and often have a more expert and precise knowledge about it compared with an insurer or another market actor who does not belong to the industry. As the nuclear operators generate the risk themselves, they are often in a better position to measure, limit and cover it. Therefore, the insurer might encounter greater difficulties than the members of a risk-sharing agreement. These members are jointly liable in the event of an accident and therefore have an incentive to prevent accidents in order to minimize their individual cost. As a consequence, the risk-sharing pool will generate a collective economic responsibility of safety. $^{49}$

Last but not least, another difference between risk-sharing and insurance concerns their respective costs. We have seen that insurance implies the payment of an annual premium which is not recoverable by the operator, whether or not there is an accident. In other words, it is a sunk cost. Conversely, as far as risk-sharing by operators is concerned, this does not require the payment of a premium but an annual individual contribution from members determined according to the criteria of risk differentiation attributed to each of them. For example, the operators, as members of the pool, can recover them should they cease their activity and therefore no longer generate the risk. These contributions are lost only if an accident occurs; they can thus be carried over as contributions for the following year if there was no accident. This allows the members to avoid excessive costs each year and to spread them over time. Each year, the contributions are updated and adjusted according to the evolution of each member's level of risk and of the expenses incurred by the pool. In this respect, contributing to the pool is a more attractive option than paying insurance premiums.

Having outlined the general principles and comparative advantages of risk-sharing we will now show how it could effectively function and be financed between European nuclear operators.

\footnotetext{
${ }^{47} \mathrm{Wu}$ and Skogh (2005).

${ }^{48}$ We will present below the differentiation criteria we rely on for our alternative.

${ }^{49}$ Skogh (1999); Faure (2004).
} 


\section{A European risk-sharing agreement: scope and financing}

\section{Principles}

Faure and Skogh ${ }^{50}$ have proposed a system of risk pooling by operators, that is, a risksharing agreement, as an alternative compensation scheme which could provide higher levels of coverage to deal with the nuclear risk. This risk-sharing could be realized through an international convention in order to secure the involvement of as many plant owners as possible. Alternatively, it could also function within the existing conventions on a voluntary basis. The risk-sharing agreement would work along the following lines:

- the operator of a nuclear power plant is strictly liable for losses caused by an accident, including third-party liability. In principle, as mentioned above, strict liability should be unlimited; ${ }^{51}$

- every plant owner should contribute to a mutual guarantee fund. This mutual fund covers their liability in the event of an accident;

- the contribution of each owner to the fund should correspond to his contribution to the risk.

Nowadays, there are also some well-known nuclear lawyers who argue in favor of such a risk-sharing agreement in Europe. ${ }^{52}$ Indeed, the European nuclear operators are all faced with the same type of risk. They all produce nuclear energy and therefore generate the same risk. Moreover, this risk can have very serious and cross-border consequences, which make it common to all of the nuclearized countries in Europe. Clearly, the European nuclearized countries are geographically close to one another and, as such, they generate cross-border risks. From this standpoint, the mutualization of their respective risk on a European scale is justified on the ground that countries mutually expose each other to a similar risk. Thus, within the pool, the members would be jointly liable and would also jointly finance the cost of repairing the damage and compensation of victims.

\section{Criteria to differentiate risk}

One of the most important points to define concerns the criteria according to which the risk differentiation will be carried out between the pool members. Indeed, to share their coverage, the members must have comparable risks which can be differentiated by reference to common criteria. Even though they are all faced with the same type of risk, the pool members do not generate the same level of risk. This level is determined by two other levels, defined by Shavell, ${ }^{53}$ which constitute our two differentiation criteria: the level of care and the level of activity. The members' level of care allows us to compare their risk by observing their individual actions taken to prevent accidents.

\footnotetext{
${ }^{50}$ Faure and Skogh (1992).

${ }^{51}$ Some European countries, such as Germany, have already implemented unlimited civil liability for their nuclear operators.

52 Pelzer (2007).

53 Shavell (1980, 1987).
} 
As far as Europe is concerned, this first differentiation would (as a minimum) require the contributing members to comply with the existing safety regulations, as implemented in the various countries, inter alia as a result of Euratom regulations. However, it may be that the probability of a risk can further be differentiated on the one hand on the basis of criteria such as the location of the nuclear power plant and on the other hand based upon construction type and operational features of the plant. ${ }^{54}$ This type of risk differentiation may provide incentives to future operators to arrive at a more appropriate decision regarding the location. Moreover, it is of course the operators themselves who have key information on the optimal construction and operational techniques for nuclear power plants. Hence, it should not necessarily be up to a regulator to indicate criteria for differentiation. Given the mutual responsibility of all members for the nuclear risk, such members obviously have incentives to develop these criteria in order to differentiate the nuclear risk themselves. Thus, we assume that the probability of being involved in an accident is the same for each reactor. ${ }^{55}$ This assumption is realistic for a number of reasons. First, all reactors in the (European) scheme are subject to the same safety regulation, which is based on the Euratom-Treaty. Hence, the level of safety to which each EU member has to conform is the same. To comply with it, each installation is made subject to specific norms corresponding to their particular size, technology or location. Secondly, the European reactors are all first and second generation reactors to which the same probability of core melt $\left(10^{-5}\right)$ applies, according to expert estimates.

The second differentiation criterion is the members' level of activity. This criterion links the operators' level of activity to the risk they generate. Indeed, even though every operator produces the same energy source, they do not run the same number of nuclear reactors and therefore do not generate the same degree of risk. It is well established that in the nuclear industry the number of reactors influences the level of risk. ${ }^{56}$ Therefore, it is crucial to make the contributions to the pool proportionally dependent upon this number. Hence, we take the number of reactors as a measure to differentiate risk on the basis of the level of activity.

\section{Potential members and hypothesis}

Theoretically, such a risk-sharing agreement could be worked out for the whole of Europe. For the moment we propose to limit the risk-sharing agreement to the Europe of the 25, thereby excluding Bulgaria and Romania. The reason for this is that

\footnotetext{
${ }^{54}$ Insurers already follow (to a modest extent) such a differentiation. For example, the Belgian nuclear insurance pool Syban differentiates between nuclear installations situated in a less populated area in the Walloon Region (near Tihange) on the one hand and those nuclear installations situated in Doel, very close to the relatively large city of Antwerp with a large population, on the other. It also takes into account the fact that Doel is closer to the sea and thus has increased risks of flooding as well as the larger potential damage in Doel than in Tihange.

55 Theoretically, a further differentiation would be possible, for example, also based on the year in which the reactor was built and on the different level of techniques used.

${ }^{56}$ NEA/OECD (1994); Schieber and Schneider (2002).
} 
Romania has a different type of reactor $^{57}$ with a supposedly increased risk, which would therefore render a risk-sharing agreement less feasible. As far as Bulgaria is concerned, like Romania, it is not subject to the same safety standards as the other EU Member States. Indeed, for a decent risk-sharing agreement to work there must be homogeneity among the members, and a risk differentiation according to level of care and level of activity must be feasible at relatively low costs. ${ }^{58}$ As we just indicated, the level of activity can be measured on the basis of the number of reactors. In addition, each of the members has to satisfy the following four conditions: $\mathrm{C} 1$, it has to be a nuclearized country; $\mathrm{C} 2$, it has to be an EU member; C3, it has to be party to international conventions; C4, it must have ratified the 1999/ 2004 Euratom Convention on nuclear safety. ${ }^{59}$ On the basis of these criteria operators in 13 EU Member States would be selected to participate in the risk-sharing agreement:

Thus, there would be 141 reactors from 13 different Member States which would participate in the risk-sharing agreement. As regards condition C3, we can observe that, among the 13 countries listed, nine are parties to the Paris and Brussels Conventions ${ }^{60}$ and four are parties to the Vienna Convention. ${ }^{61}$ Although these Conventions were not drafted by the same organization (NEA/OECD for the first and IAEA for the second), they are very similar. Indeed, on the one hand, they are based on the same general principles of tort law and, on the other, they are linked by a Joint Protocol signed in 1988, designed to harmonize them. Furthermore, all of these Conventions have recently undergone similar changes (i.e. increased cap and increased compensation capacity). Consequently, despite the fact that the 13 participating countries belong to different liability conventions, it is still relevant to bring them together in the risk-sharing (see Table 1).

Let us now address the issue of how potential damage amounting to $€ 10$ billion could be financed under various systems through contributions from these different operators running the 141 reactors.

${ }^{57}$ We can find five types of nuclear reactors in the EU: Pressurized Water Reactors (PWR, the most common), Pressurized Heavy Water Reactors (PHWR, in Romania), Gas Cooling Reactors (GCR, in the U.K.), Boiling Water Reactors (BWR) and Light Water Graphite Reactors (LWGR, the Lithuanian reactor).

${ }^{58}$ Skogh (2007).

59 As far as nuclear safety is concerned, Euratom acceded to the 1994 Convention on Nuclear Safety through the Commission Decision 1999/819/Euratom of 16 November 1999. This Convention was drafted by the IAEA in order to improve nuclear safety worldwide. The Convention has three main objectives: to achieve and maintain a high level of nuclear safety through the enhancement of national measures and technical cooperation; to establish and maintain effective defences against radiological hazards in nuclear installations in order to protect people and the environment, etc.; and to prevent nuclear accidents and limit their consequences. The Commission Decision 1999/819/Euratom was revised in 2004 to integrate the new members as of this date.

${ }^{60}$ These countries are Germany, Belgium, Spain, Finland, France, the Netherlands, the UK, Slovenia and Sweden.

${ }^{61}$ These countries are Lithuania, the Czech Republic, Slovakia and Hungary. 
The Geneva Papers on Risk and Insurance - Issues and Practice

306

Table 1 Participating countries

\begin{tabular}{lc}
\hline Countries members & Number of reactors \\
\hline Belgium & 7 \\
Czech Republic & 6 \\
Finland & 4 \\
France & 58 \\
Germany & 17 \\
Hungary & 4 \\
Lithuania & 1 \\
Netherlands & 1 \\
Slovakia & 5 \\
Slovenia & 1 \\
Spain & 8 \\
Sweden & 10 \\
UK & \\
Total & 19
\end{tabular}

${ }^{a}$ On 1 January 2007, the UK shut down two reactors in Dungeness and two others in Sizewell definitively.

\section{Financing methods}

The starting point for the financing of the compensation (i.e. making the $€ 10$ billion available at the moment the accident happens) is of course that the role of the State should be minimized. Thus, the intervention by the State through public funds (as is the case today in Europe) would be excluded in order to promote risk internalization. As a consequence, the entire amount of $€ 10$ billion would have to be generated through private funds. So how would the operators contribute to the risk-sharing? Obviously, the type of the contributions would affect the incentives and the costs of the risk-sharing and hence its efficiency. We will examine three types of contributions.

Contributions paid ex ante

A first possibility is that operators would be required to make the full contribution ex ante. Here we refer to the fact that, based on the life span of the reactors and the number of reactors an operator would run, it would pay its contribution to the pool ex ante. This would therefore be risk-related (to level of care and activity level) and the funds would be invested by the institution running the risk-sharing agreement. The advantage of this first model of directly paid contributions ex ante is of course that the funds would be available in the event of an accident. The major disadvantage is that one does not know whether all of the operators will suffer an accident. For the life span of the operation assets would be immobilized and the costs may be huge. A difference with insurance (as we saw above) is that the contribution is not necessarily lost but can be returned after the life span of a reactor (assuming of course that no accident occurred). Still this model has the advantage that there is a degree of risk-spreading as the operator obviously does not have to contribute the $€ 10$ billion immediately, but only a small proportion, corresponding to its contribution to the risk. However, a major disadvantage remains that large sums will have to be made 
available in this model. In fact, the sums may potentially be so large that they could lead to the insolvency of some operators, especially smaller ones. We note this system of contributions as $C p$. As regards the cost of these contributions, the operator must take into account the fact that the contribution will be immobilized over 40 years if no accident occurs and that it could be lost at any moment during the life span of its operation if an accident does occur. Furthermore, we assume that there can be only one nuclear accident over the period. Thus, the total cost of the operator's contribution, noted as $Z_{C p}$, is calculated with the following formula (based on the same reasoning as Eq. (C.2) in Appendix C):

$$
Z_{C p}=\left[C p-\frac{C p \cdot(1-p \cdot n)}{(1+a)^{40}}\right]+\left[+\sum_{t=1}^{t=40} \frac{C p \cdot(p \cdot n)}{(1+a)^{t}}\right]
$$

$p$ again being the probability of an accident, with $p .=p_{i} \cdot p_{j}^{\prime}, t=40$ the (current) average life span of a reactor, $n$ the number of reactors run by the operator in question and $a$ the discount rate over the period. For our calculations, we will use the same value of $p$ as used before (see Appendix A). As far as $a$ is concerned, we use the discount rate used by EDF, that is, $a=3$ per cent.

Contributions reserved ex ante

A second model is the one whereby contributions are not paid, but reserved by operators on an ex ante basis. Of course, all of the aforementioned problems with reserves again apply here: one has to ensure that the amount set aside for the reserve is available in the event of an accident. Hence there can be high administrative costs related to the control of the reserves in the operator's account on the part of the regulator. Moreover, some priority regulation needs to be made in order to ensure that the trustee in bankruptcy cannot seize the funds. We note these contributions as $C v$. Finally, we also indicated that with reserves set aside ex ante there are also serious costs involved, not to mention that reserves lack any element of risk-spreading. Relying on the section on reserves and on Eq. (C.2) in Appendix C, the total cost of these reserved contributions, noted as $Z_{C v}$, is calculated using the following formula:

$$
Z_{C v}=\left[C v-\frac{C v \cdot(1-p \cdot n)}{(1+k)^{40}}\right]+\left[\sum_{t=1}^{t=40} \frac{C v \cdot(p \cdot n)}{(1+k)^{t}}\right]
$$

\section{Retrospective contributions by operators}

A third alternative, followed in the U.S. Price-Anderson Act for the second layer of compensation (see the section on risk-sharing), is a so-called retrospective contribution by operators. In this case, operators do not actually have to set aside a reserve or pay a contribution ex ante. They merely pay a retrospective premium after an accident has occurred. In the U.S. the payment to the victims is guaranteed by the NRC. This NRC reclaims the compensation paid to the victims via the retrospective premiums. The amount of the premium each operator has to contribute is fixed by statute and 
currently limited to $\$ 15$ million per year. The total amount available within this second layer is $\$ 10.461$ billion. Since 103 U.S. reactors participate in the scheme, the financial risk for each reactor is $\$ 10.461$ billion in total: $103=\$ 101.56$ million. ${ }^{62}$ The advantage for the operator is obviously that no assets are immobilized until a nuclear accident occurs. The advantage for the victims is that the NRC guarantees payment. One might think there may be a risk of insolvency, as payments are only made ex post through these retrospective contributions. However, in the nuclear regulatory context, this should not necessarily be a major problem since insolvency of nuclear energy producers is often controlled via other devices as well. Moreover, in the event of insolvency of one of the members of the pool the total compensation due would remain the same, meaning the contribution of each operator would simply increase. This would provide an incentive to the group of operators to engage in mutual monitoring, not only with respect to safety but also with respect to the solvency of the other operators. This model works well in the U.S. where this mutual monitoring is apparently possible.

One important question, however, remains, that is, whether the payment of retrospective contributions is already taken into account in current prices of nuclear energy. In theory, that should be the case since operators should today calculate the probability that they may in the future be exposed to the risk of having to contribute via retrospective premiums. In the current U.S. model it is not entirely clear whether such a passing on of a future retrospective premium on current prices for nuclear energy effectively takes place. If that were not the case, the danger would exist that the risk is merely shifted to the future users of energy, who would then have to pay a higher price. In that scenario there would be a redistribution to future generations. This may not only be inefficient, but could also be problematic from a distributional perspective. So what would be the cost of such retrospective contributions? We note this cost as $Z_{C r}$. As previously mentioned, even though these contributions, noted as $\mathrm{Cr}$, are only paid ex post, operators should calculate the probability that they may in the future be exposed to the risk of having to contribute via retrospective premiums. This possibility is equivalent to calculating the expected cost of losing this retrospective contribution, if an accident occurs. Moreover, as stated in the section on risk-sharing, given that the retrospective contributions are only paid ex post, they must be supported by a guarantee provided by the operators to the regulator. Are these guarantees costly? The U.S. General Accounting Office (GAO) holds that today, the U.S. operators use as a guarantee either the certification by the NRC of their financial statements, or a payment bond contract executed with the ANI which obliges the operators to pay the retrospective premiums in the event of an accident. ${ }^{63}$ Those guarantees are not costly for the operators. On the one hand, the certification of their financial statements consists first in the publication of the operators' balance sheets and only then in the confirmation by the NRC that the operators would have sufficient assets to pay their premiums (if the balance sheets are considered to be significant). Therefore, it does not imply any cost for the operators. On the other hand, the bond

\footnotetext{
${ }^{62}$ Faure and Vanden Borre (2007).

${ }^{63} \mathrm{GAO}(2004)$.
} 
contract is only a formal engagement. It is thus not costly either. Nevertheless, other types of acceptable guarantee are proposed in the NRC regulations: surety bonds, letters of credit, revolving credits or escrow deposits in government securities. ${ }^{64}$ If the operators used one of these other means, the cost of guarantee would therefore be positive. As a result, the total cost of retrospective premiums is shown by the following formula:

$$
Z_{C r}=\left[\left(\sum_{t=1}^{t=40} \frac{C r \cdot(p \cdot n)}{(1+a)^{t}}\right)+G\right]
$$

$G$ is the cost of the guarantee. For the nuclear operators, $G=0$.

In the 13 countries considered for our alternative solution, there are 28 operators. So what would be the operators' contributions and costs under these three models? Using Eqs. (1)-(3), Table 2 lists the respective contributions and costs of participating operators according to their number of reactors.

It is important to note that whichever model of operators' contributions is adopted, their amount will be always the same. In other words, we will always have $C p=C v=C r$. Only their respective costs, $Z_{C p}, Z_{C v}$ and $Z_{C r}$ will be different. These contributions are expressed in "million $€$ per year". This does not mean that these amounts have to be paid each year by the operators but that each year they have to be made available. If no accident occurs one year, the amounts are carried forward to the following year.

We can observe that the contribution per reactor per year amounts to $€ 70.9$ million (i.e. 0.7 per cent of the total). As a result, the risk differentiation allows the smallest operators to pay much less than the bigger ones. Given that EDF alone operates 58 nuclear reactors, it would have to contribute a significant proportion of the risksharing (up to 41.1 per cent) and therefore bear a high cost $(70.9 \times 58=€ 4,112$ million). Is the risk-sharing cheaper than the alternatives (insurance and reserves)?

As far as insurance is concerned, the risk-sharing seems, at first sight, to be individually more expensive. Indeed, as stated above, in order to cover $€ 10$ billion with insurance, an operator would have to pay a premium equal to $€ 37.3$ million per reactor per year. Yet, €37.3 million $<€ 70.9$ million. Nevertheless, in contrast to contributions, which can be carried forward if no accident occurs, insurance premiums are lost each year, whether there is an accident or not. Therefore, as regards Table 2, insurance would be cheaper than risk-sharing only if there were an accident every year. Indeed, in this case, the operator's annual cost of covering the damage would amount to $€ 37.3$ million with insurance, as compared to $€ 70.9$ million $+Z_{C i}$ with the risksharing. Conversely, if the frequency of an accident is lower (i.e. if there is an accident every two years or more), the insurance is more costly. Indeed, it is enough if there is an accident every 2 years for the cost of insurance to exceed the cost of contributions $\left(€ 37.3\right.$ million $\times 2=€ 74.6$ million $>€ 70.9$ million $+Z_{C i} \times 2$, with $0.004 \leqslant Z_{C i} \leqslant 1.8$ and $G=0)$. As regards the current probability of an accident $\left(10^{-5} \times 0.81\right.$ or $\left.10^{-5} \times 0.19\right)$, we can see that the cost of insurance would clearly be higher than the cost of contributions. If no accident occurs over the period, this is even more the case. In this case, the insurance would cost $€ 37.3$ million $\times 40=€ 1.5$ billion per reactor, whereas the 
Table 2 The contributions and annual costs of participating operators according to their number of reactors

\begin{tabular}{|c|c|c|c|c|c|c|c|}
\hline \multirow[t]{3}{*}{ Countries } & \multirow{3}{*}{$\begin{array}{l}\text { Nuclear operators } \\
\text { (Number of reactors) }\end{array}$} & \multirow{3}{*}{$\begin{array}{l}\text { Share } \\
(\%)\end{array}$} & \multirow{3}{*}{$\begin{array}{c}\text { Contributions amount } \\
C i(i=p, v, r) \quad(m € / \text { year })\end{array}$} & \multicolumn{4}{|c|}{ Contributions cost $\left(Z_{C i}\right)(i=p, v, r) \quad(m € /$ year $)$} \\
\hline & & & & \multirow[t]{2}{*}{$Z_{C p}$} & \multicolumn{2}{|c|}{$Z_{C v}$} & \multirow[t]{2}{*}{$Z_{C r}$} \\
\hline & & & & & $k=8.6 \%$ & $k=13 \%$ & \\
\hline Belgium & Electrabel NP (7) & 5 & 496.5 & 8.6 & 11.9 & 12.3 & $0.02+\mathrm{G} / 40$ \\
\hline Czech Republic & CEZ (6) & 4.3 & 425.5 & 7.3 & 10.2 & 10.5 & $0.015+\mathrm{G} / 40$ \\
\hline \multirow[t]{4}{*}{ Spain } & ANAV (3) & 2.1 & 212.8 & 3.7 & 5.1 & 5.3 & $0.0037+\mathrm{G} / 40$ \\
\hline & CNAT (3) & 2.1 & 212.8 & 3.7 & 5.1 & 5.3 & $0.0037+\mathrm{G} / 40$ \\
\hline & Iberdrola (1) & 0.7 & 70.9 & 1.2 & 1.7 & 1.8 & $0.0004+\mathrm{G} / 40$ \\
\hline & Nuclenor (1) & 0.7 & 70.9 & 1.2 & 1.7 & 1.8 & $0.0004+\mathrm{G} / 40$ \\
\hline \multirow[t]{2}{*}{ Finland } & Fortum (2) & 1.4 & 141.8 & 2.5 & 3.4 & 3.5 & $0.0016+\mathrm{G} / 40$ \\
\hline & TVO (2) & 1.4 & 141.8 & 2.5 & 3.4 & 3.5 & $0.0016+\mathrm{G} / 40$ \\
\hline \multirow[t]{8}{*}{ Germany } & RWE (2) & 1.4 & 141.8 & 2.5 & 3.4 & 3.5 & $0.0016+\mathrm{G} / 40$ \\
\hline & EON (5) & 3.5 & 354.6 & 6.2 & 8.5 & 8.8 & $0.01+\mathrm{G} / 40$ \\
\hline & KKW B. (1) & 0.7 & 70.9 & 1.2 & 1.7 & 1.8 & $0.0004+\mathrm{G} / 40$ \\
\hline & KKW L. (1) & 0.7 & 70.9 & 1.2 & 1.7 & 1.8 & $0.0004+\mathrm{G} / 40$ \\
\hline & KKW Gro (1) & 0.7 & 70.9 & 1.2 & 1.7 & 1.8 & $0.0004+\mathrm{G} / 40$ \\
\hline & KKW Gru (2) & 1.4 & 141.8 & 2.5 & 3.4 & 3.5 & $0.0016+\mathrm{G} / 40$ \\
\hline & KKW K. (1) & 0.7 & 70.9 & 1.2 & 1.7 & 1.8 & $0.0004+\mathrm{G} / 40$ \\
\hline & EnBW (4) & 2.8 & 283.7 & 4.9 & 6.8 & 7 & $0.006+\mathrm{G} / 40$ \\
\hline
\end{tabular}


Table 2 (continued)

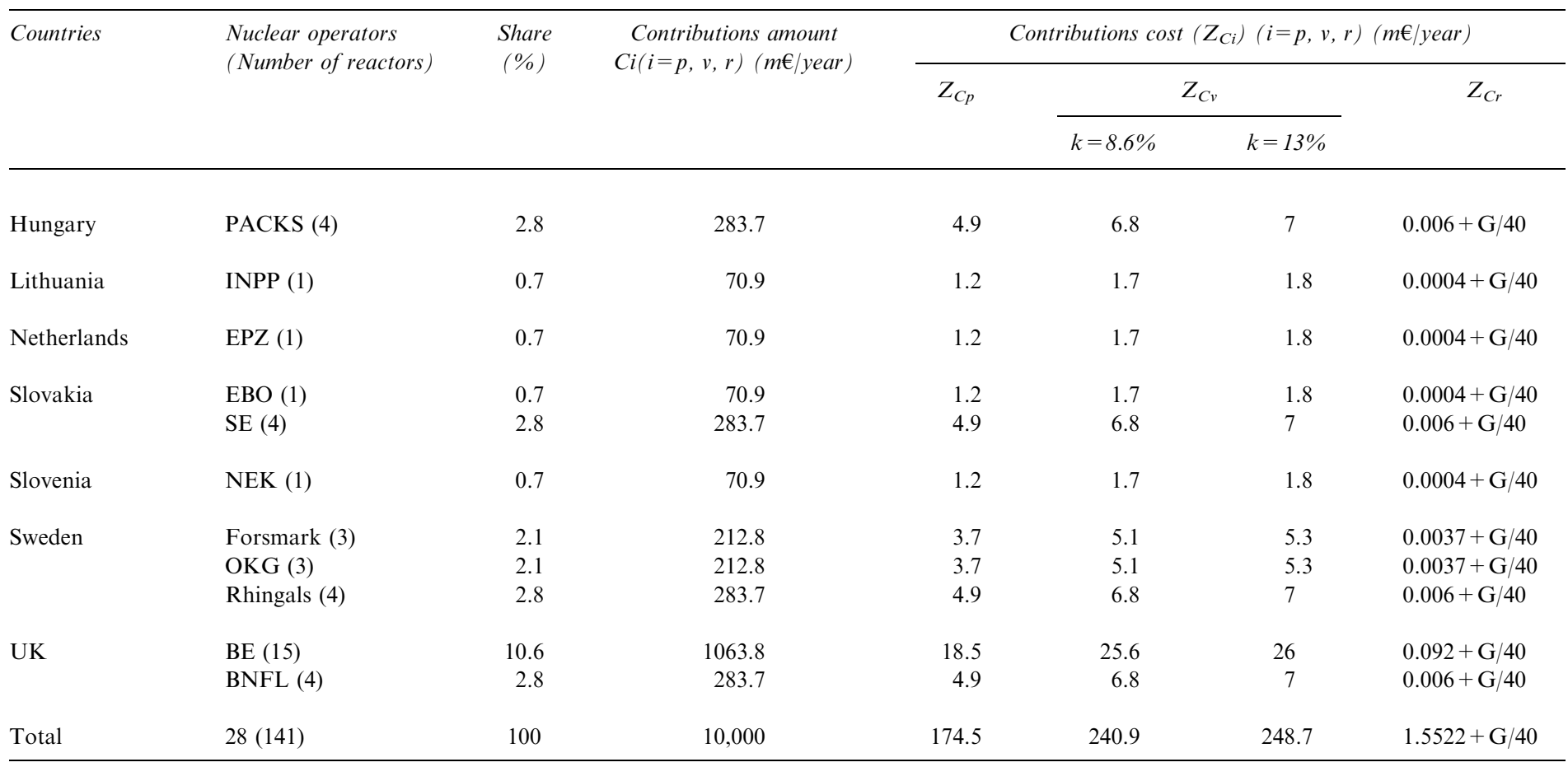


The Geneva Papers on Risk and Insurance - Issues and Practice

312

Table 3 Comparison between the costs of reserves and of the risk-sharing (for $G=0$, in million€)

\begin{tabular}{lcc}
\hline & Cost of reserves & Cost of the risk-sharing \\
\hline Small operator (Nuclenor, KKW B., ..) $(n=1)$ & 9,632 (low evaluation) & $0.16 \leqslant Z_{C i} \times 40 \leqslant 72$ \\
& 9,924 (high evaluation) & \\
Big operator (EDF) $(n=58)$ & 9,720 (low evaluation) & $55 \leqslant Z_{C i} \times 40 \leqslant 4100$ \\
& 10,000 (high evaluation) & \\
\hline
\end{tabular}

risk-sharing would only cost $Z_{C i} \times 40$, that is, between $€ 0.16$ million and $€ 72$ million per reactor (for $G=0$ ). The only situation where the risk-sharing would be more expensive than the insurance would be for the contributions $Z_{C r}$, with $G=€ 1.4$ billion, which is prohibitive (and unlikely).

Compared to reserves for self-insurance, the risk-sharing is cheaper. Indeed, we mentioned above that, to set aside each $€ 10$ billion of reserves, the annual cost would amount to $€ 240.8$ million (low evaluation) or to $€ 248.1$ million (high evaluation) for one reactor operated. According to Table 3, this means that, if no accident occurs over the period, the smallest suppliers (such as the Spanish Nuclenor or the German KKW B.), would have to bear a total cost of $€ 240.8$ million $\times 40=€ 9,632$ million (low evaluation) or $€ 248.1$ million $\times 40=€ 9,924$ million (high evaluation), while the biggest supplier (EDF) would have to bear a total cost of $€ 242.4$ million $\times 40=€ 9,696$ million or $€ 249.2$ million $\times 40=€ 9,968$ million. These costs would even be higher if an accident occurred over the period, since reserves up to $€ 10$ billion would have to be replenished in the meantime. As regards the risk-sharing, and as we mentioned in the preceding paragraph, the total cost over the period for the smallest suppliers would be $€ 0.16$ million $\leqslant Z_{C i} \times 40 \leqslant € 72$ million (for $G=0$ ). For EDF, this cost would amount to $€ 55$ million $\leqslant Z_{C i} \times 40 \leqslant € 4,100$ million (for $G=0$ ) (see Table 2). Table 3 allows us to compare these results.

Under the constraints assumed above (insurance would be cheaper than risk-sharing if there were an accident every year, there is one case for which insurance can be cheaper than reserves.) Insurance would cost $€ 37.3$ million per reactor per year whereas reserves would cost $€ 240.8$ million (low evaluation) or $€ 248.1$ million (high evaluation) per year for one reactor operated. We have seen in the section on reserves that reserves are more attractive to big operators (which run many reactors) than to small ones. As a matter of fact, insurance is cheaper than reserves in the case of up to seven reactors in operation $(1<n<7)$. Indeed, in this case, reserves would cost $€ 240.9$ million (low evaluation) or $€ 248.2$ million (high evaluation) per year, that is, $€ 34.4$ million or $€ 35.5$ million per reactor per year.

Aside from this particular case, we can conclude that, whether there is an accident or not, the cost of reserves always exceeds the cost of the risk-sharing, under the conditions defined in this model.

The same conclusion applies to the global cost of the risk-sharing. For 141 reactors and 28 operators, the total insurance to cover $€ 10$ billion would cost $37.3 \times 141=€ 5.3$ billion per year, while the reserves would cost $€ 25$ million per year (low evaluation) or $€ 253$ million per year (high evaluation). These costs are higher than the total cost of the risk-sharing, which amounts at most to $€ 248.7$ million $\left(Z_{C v}\right)$ (see Table 2). As far as 
the contributions are concerned, the retrospective contributions appear to be the cheapest. Of course, the cost of the retrospective contributions depends on the value of $G$, which (on the basis of our information) is zero in the American case. If $G>0$ and high, it is possible then that the retrospective contributions become more expensive than the other types of contributions.

\section{Legal consequences}

As far as the legal consequences of implementing a risk-sharing agreement are concerned (no matter how it would be financed) we can be brief: first of all, our model starts by assuming an unlimited liability for nuclear operators. This is already possible within the NEA/OECD Conventions. At least those states that wish to do so can impose unlimited liability (like Germany). However, the principle in the conventions is still limited liability, so in that respect the conventions would have to be changed. Secondly, the conventions would also have to be changed since there would no longer be an injection of public funds. It should be borne in mind that under the current NEA/OECD Convention there is a substantial amount of State subsidy which would be completely eliminated if a risk-sharing agreement were to be adopted. Thirdly, it is likely that, as per the model of the Price-Anderson Act in the U.S., the current conventions would have to be replaced by a totally new convention which merely provides the institutional support and framework for a risk-sharing agreement between operators. This new convention should for example regulate the payment to victims through an agency and the way in which this agency can claim contributions (ex ante or ex post) from operators.

\section{Role of the state}

In principle within a risk-sharing agreement there should not necessarily be any role for the State or for public authorities since risk-sharing could be based upon an agreement between nuclear operators. However, given the large externality risk caused by a nuclear accident and the socially beneficial character of such a risk-sharing agreement, it could be argued that governments should intervene to facilitate the risksharing agreement, especially as far as compensation to victims is concerned. Hence, some authority should guarantee compensation to the victims at the European level. This could either be an existing authority (through Euratom) or a new European Nuclear Regulatory Agency (ENRC) modelled on the U.S. NRC. The most important task for this regulatory agency would be to collect contributions from the operators and to compensate the victims. In case of ex ante payments the assets would already be available with the agency. Should only retrospective payments be claimed, the agency would pre-finance the compensation and later collect the money from the operators. Thus, a form of public-private partnership would be created with the simple advantage that the government would merely administer the risk, but would not run any direct risk itself. Hence, since there is no financing of the compensation through government the problematic subsidization aspect of the current system is eliminated.

This role for government complies with a tendency in the financial compensation for victims of (other) catastrophes whereby governments increasingly play a rather 
supplementary role, especially in cases where insurance markets fail. More particularly, in the U.S. the California Earthquake Authority and the National Flood Insurance Plan provide examples of cases where governments facilitate the functioning of insurance markets through public-private arrangements. ${ }^{65}$ In other legal systems one can also increasingly observe the use of these public-private partnerships to finance catastrophic risks. ${ }^{66}$ Moreover, a similar model is applied in respect of the compensation of victims of damage from oil pollution. Victims can call on the International Oil Pollution Compensation Fund, based in London. The IOPC merely administers the contributions which it collects from oil receivers. This IOPC has also been made possible through an institutional framework provided by an international convention. ${ }^{67}$

In addition to the creation of this regulatory agency, one could of course imagine other roles for the State. For example, the question arises whether it should be the State which fixes the rules governing the contribution of each particular operator (as is the case in the Price-Anderson Act). As long as these contributions are risk-related and therefore linked to the level of care and activity of operators, this is not a problem. However, the system should then be construed in such a way that the superior expertise of operators themselves as regards reactor safety is also used to determine the criteria for this differentiation of the contributions. Moreover, the institutional framework could also fix the yearly amount to be paid by each contributor (modelled on the Price-Anderson Act) if contributions were not paid ex ante but in a retrospective manner. Thus the individual exposure of each operator could still be limited. Furthermore, State authorities will always play an important role in controlling nuclear safety within reactors, as is the case today.

\section{Conditions for implementation}

That Europe should abolish the current system of limited liability of the operator of a nuclear power plant combined with large state subsidies, and that risk-sharing by operators could generate better results, are propositions that have been advanced in the law and economics literature for some time. In this paper we outlined how such a risk-sharing agreement could be shaped and financed. It is of course a quite different issue whether it is likely that such an agreement will also be established in Europe. That this is theoretically possible is demonstrated by the U.S. Price-Anderson Act, whereby in the second layer an amount of more than 10 billion U.S. dollars in compensation can be generated. In Europe, the number of operators is even greater than in the U.S. (141 compared to 103), so it is certainly possible to come to a similar arrangement in Europe. However, there are a number of considerable differences. First of all, the U.S. Price-Anderson Act is drafted by the U.S. legislator on the basis of an open and transparent process in which all interests (not solely those of the nuclear lobby) can be heard. Thus it is not surprising that, within this U.S.

\footnotetext{
${ }^{65}$ Rabin and Bratis (2006).

${ }^{66}$ See Faure (2006, p. 425).

${ }^{67}$ On the question whether this IOPC Fund constitutes a private or public arrangement, see Wang (2007).
} 
Price-Anderson model, a shift has taken place from a system where part of the compensation was initially paid by the State to a model in which State intervention has completely disappeared. However, in the European context the conventions (which are subsequently implemented by the States) are drafted by the OECD Nuclear Energy Agency. In this agency technical expert-representatives of the participating states intervene and prepare the legislative proposals. The underlying process on which this is based seems to be quite opaque. After the conventions have laid down the framework, Member States have to implement it and there is no further deliberation of the context. Hence, within the European context the legislative power lacks a countervailing power which would represent the interest of the public at large as a counterweight to the nuclear lobby. In that respect, previous research has shown that nuclear liability legislation can be largely qualified as the result of effective lobbying by interest groups. $^{68}$

Secondly, in the U.S., where nuclear technology is comparable and information can flow freely between the states, it is relatively easy for the 103 operators to mutually monitor each other's safety and activity level as well as their solvency. Therefore, in the U.S. context a risk-sharing agreement based on mutuality and solidarity will also be acceptable to operators as they can monitor their competitors at low cost. However, within the European context such monitoring may be far more difficult. One reason for this is that the types of operators are different. In some cases the operators are completely State-owned (as in France) whereas that is not the case in others. For operators to be willing to engage in a risk-sharing agreement it is of course crucial that they are able to monitor the safety of their competitors' reactors as well as their potential solvency. Indeed, the principle of mutuality in a risk-sharing agreement entails that each European operator would be required to contribute to the compensation resulting from an accident on any of the participating installations. Moreover, if there may be a solvency problem with one of the operators, the others' share could increase. Hence, in order to make such a risk-sharing agreement feasible, one important condition is that an institutional framework must be created whereby operators are assured that they can either monitor the safety of all participating operators' reactors themselves, or that they can rely on the monitoring performed by a regulatory agency entrusted with this task. In other words, there should be equal or at least comparable levels of nuclear safety and security. ${ }^{69}$ Such transboundary safety control has been initiated, for example in the association WENRA, which groups together the Western European Nuclear Regulatory Authorities.

Thirdly, it can be noted that in the European risk-sharing model, the contribution per reactor is lower ( $€ 70.9$ million) than in the U.S. model ( $\$ 100.6$ million) since (logically) the number of reactors in Europe is greater.

Finally we can reiterate the warnings previously formulated at a conference in 1984, namely that the amount of compensation for victims of nuclear accidents in Europe is also so low because a large part of the available capacity is in fact reserved for first-party insurance, which covers the property damage to the installation (see

\footnotetext{
${ }^{68}$ Faure and Van den Bergh (1990).

${ }^{69}$ Pelzer (2007, p. 51).
} 
footnote 17). If one wishes to give priority to the compensation of victims, it is important to separate the amount available for third-party liability from the coverage for the installation itself and to give priority to the compensation to victims. This is of course precisely the goal of the risk-sharing agreement as we have proposed it.

\section{Conclusions}

The liability of an operator of a nuclear power plant has been criticized in law and economics literature for some time. The limit on the liability of the operator, the exclusive channelling of the liability to the operator and the large amounts of state intervention were always criticized for obvious reasons: a lack of internalization of the potential costs of a nuclear accident and a potential danger of underdeterrence. Moreover, it was also often held in legal literature that the regime introduced in the 1950s under the NEA/OECD may have been justified 50 years ago, when the development of nuclear energy was in its infancy, but probably not any longer today. However, many have also argued that the nuclear risk is a particular type of risk, involving large uncertainties concerning both the probability and the damage, whereby the potentially catastrophic magnitude of the damage is an additional problem. In that respect, it is an important issue open to and requiring discussion. These features have traditionally made it difficult for insurance markets to cover the nuclear risk. The effect has been that traditional insurance policies have frequently excluded the nuclear risk from coverage and specifically for this nuclear risk, insurance companies created at the national level insurance pools whereby capacity was brought in on a noncompetitive basis. However, today it seems as if these nuclear insurance pools actually serve to inhibit rather than promote the coverage of the nuclear risk since the amounts they generate are relatively modest, especially within the European context.

Given the significance of the nuclear risk today (of course connected to the climate change problem), it can be argued that a compensation system has to be worked out that guarantees at least a minimum level of compensation for victims and ensures a better internalization of the nuclear risk, thereby also eliminating the subsidy currently provided by public authorities. Both in the literature and in practice, a variety of alternatives have been developed. One alternative that was suggested in the literature in the early 1990s was the creation of a risk-sharing agreement between operators. It has been argued that the risk-sharing agreement has the particular advantage that specific knowledge on probabilities is not necessary ex ante provided that operators can mutually monitor each other. Moreover, an example of such a (regulatory) risksharing agreement can be found in the U.S. Price-Anderson Act, under which a second layer of compensation (of over 10 billion U.S. dollars) is provided by all 103 operators in the U.S.

The aim of our paper was to seriously consider the suggestions made in the literature and to examine potential alternatives for covering the nuclear risk. The starting points for developing these alternatives were firstly that an amount would have to be generated (according to the various scenarios in the literature) sufficient to provide compensation in case of an average nuclear accident. For that reason, an amount of $€ 10$ billion was taken, which incidentally also more or less corresponds to the amount currently available in the U.S. Already this would be significantly higher than the total 
amount of compensation currently available under the NEA conventions. After the implementation of the most recent protocols, this amount will be $€ 1.5$ billion, of which $€ 800$ million will continue to be financed through State aid. Secondly, the compensation should in principle be generated by nuclear operators themselves; State intervention should be abolished in order to promote internalization of the nuclear risk or, at the very least, its role should be rethought. ${ }^{70}$ Thirdly, we examined alternatives which are realistic in the sense that they already exist unlike, for example, the use of capital markets to cover the nuclear risk, which has been advanced in the literature but has not yet been applied in practice.

On the basis of these starting points, there are basically three alternatives which could be used to generate this amount of $€ 10$ billion. The first alternative is to use insurance. However, the experience of France tells us that premiums are exceptionally high, probably due to the monopolistic nature of the nuclear insurance pool, risk aversion on the part of the pools, possible high loading costs, etc. We calculated that this premium would be $€ 37.3$ million per reactor per year to cover $€ 10$ billion, which is clearly prohibitive. The same problem arises with the second alternative currently used in practice, namely the setting aside of reserves for the loss. Reserves are of course only possible if the operator is able to generate these high amounts. In practice, only Stateowned operators would be able to generate these high amounts through their own reserves. Based on earlier research and applying the Capital Asset Pricing Model, we showed that the cost of reserves is high for operators.

We then turned to the alternative of risk-sharing and outlined three possible ways of financing a risk-sharing agreement. The first possibility is that an operator pays contributions ex ante. Within this model, it shares the risk with other operators on the basis of the number of reactors, but the major disadvantage is of course that the assets will have to be paid ex ante. The second possibility is to set aside reserves ex ante. A problem that arises in this case from society's perspective is that control devices are necessary to guarantee that the whole amount of the reserve will be available. The third alternative is the one currently used in the U.S., namely the payment of retrospective contributions (after an accident has occurred) by operators.

The calculations showed that the retrospective contributions seemed to be a cheap way of participating in the risk-sharing. However, this assumed that the cost of guarantee is zero or low. More importantly, we also showed that (no matter how it is financed) risk-sharing is substantially cheaper than the current model of compensation through insurance and reserves, under the conditions defined in our model. Not only does the risk-sharing make it possible to generate higher amounts of compensation for victims, but it also allows a risk differentiation whereby smaller operators pay less than the bigger ones.

Of course, the model presented here could be refined further. For example, we assumed that the total amount of compensation will be provided through contributions paid by operators. In our model the State intervenes merely as an

${ }^{70}$ Skogh (2007) proposed that the liability in the event of an accident be transferred to States. The States' liability should thus be recognized by the law. He then proposed a risk-sharing system between States in the EU. 
intermediary to pre-finance compensation to victims and subsequently claims it back from operators (in the event of contributions being paid ex post). Thus, in our model, there is no State intervention in the compensation itself and hence no subsidizing effect. However, it would be feasible to imagine that the State might play a role for example as a reinsurer (in cases where reinsurance fails). In addition, our model completely excludes insurance or reinsurance. However, further refinements would be possible whereby for example a part of the contribution due from the operator would be financed through (re)insurance. There are also many other issues relating to the compensation of victims of nuclear accidents which we could not address and which merit further research. This concerns for example the question of how to deal with health consequences which have to be determined through the application of the doseeffect relationship in case of exposure to low doses.

Finally, we briefly touched upon the fact that some may argue that this model has largely been developed from the ivory tower of academia and that it may be far more difficult to implement it effectively in practice. We do realize that operators today largely benefit from the current system with low financial limits and large State subsidies. Accordingly, there may be opposition from nuclear interest groups to the implementation of such a model. In addition, other institutional features (such as differences in regulatory structures between European Member States) may also inhibit the creation of the risk-sharing model outlined in this paper. Nevertheless, these should not necessarily constitute reasons against the implementation of such a model, but rather reasons to develop further research on the institutional and sociopolitical conditions that would have to be fulfilled in order to implement a compensation model for nuclear accidents that leads to a better (even if not optimal) internalization of the nuclear risk.

\section{References}

Betbèze, J.P. and Bentoglio, G. (2005) L'Etat et l'assurance des risques nouveaux, Commissariat général du plan, Paris: La Documentation Française.

Carrez, G. (2003) Rapport fait au nom de la Commission des Finances, de l'Economie Générale et du Plan sur le projet de loi de finances rectificative pour 2003 ( $n^{\circ} 1234$ ), Rapport de l’Assemblée Nationale, $n^{\circ} 1266$, tome II, Paris.

Dimson, E., Marsh, P. and Staunton, M. (2001) Triumph of the Optimists: 101 Years of Global Investment Returns, Princeton, NJ: Princeton University Press.

Dow, J. (1985) 'The organization and development of international liability capacity and national market pools, with special reference to new nuclear countries', in OCDE (ed) La responsabilité nucléaire et l'assurance, Paris: OECD, pp. 172-182.

Dubin, J.A. and Rothwell, G.S. (1990) 'Subsidy to nuclear power through Price-Anderson liability limit', Contemporary Economic Policy 8(3): 73-79.

EDF (Electricité de France) (2005) Document de Reference, Paris: EDF Group.

ELINI (European Liability Insurance for the Nuclear Industry) (2005) Annual Report 2005, Brussels, Belgium (http://www.elini.net).

EMANI (European Mutual Association for Nuclear Insurance) (2005) Annual Report 2005, Brussels, Belgium (http://www.emani.be).

Faure, M. (1995) 'Economic models of compensation for damage caused by nuclear accidents: Some lessons for the revision of the Paris and Vienna Conventions', European Journal of Law and Economics 2: 21-43.

Faure, M. (2004) 'Alternative compensation mechanisms as a remedy for insurability of liability', The Geneva Papers on Risk and Insurance - Issues and Practice 29: 455-489. 
Faure, M. (2006) 'Comparative and policy conclusions', in M. Faure and T. Hartlief (eds) Financial Compensation for Victims of Catastrophes. A Comparative Legal Approach, Vienna: Springer, pp. 389-452.

Faure, M. and Fenn, P. (1999) 'Retro-active liability and the insurability of long-tail risks', International Review of Law and Economics 19: 487-500.

Faure, M. and Fiore, K. (2006) An economic analysis of the French nuclear liability subsidy, Working Paper, Centre d'Analyse Economique Aix-Marseille, France.

Faure, M. and Hartlief, T. (2003) Insurance and Expanding Systemic Risks, Paris: OECD.

Faure, M. and Skogh, G. (1992) 'Compensation for damages caused by nuclear accidents: A convention as insurance', The Geneva Papers on Risk and Insurance - Issues and Practice 17: 499-513.

Faure, M. and Van den Bergh, R. (1990) 'Liability for nuclear accidents in Belgium from an interest group perspective', International Review of Law \& Economics 3: 241-254.

Faure, M. and Van den Bergh, R. (1995) 'Restrictions of competition on insurance markets and the applicability of EC antitrust law', Kyklos 48: 65 et seq.

Faure, M. and Vanden Borre, T. (2007) The US versus the International Nuclear Liability and Insurance System: An Economic Analysis, paper presented at the joint conference of the European Association for Law and Economics (EALE) and The Geneva Association for the Study of Risk and Insurance, Lecce, 15-16 June 2007.

Fiore, K. (2006) The subsidy of the French nuclear power: An empirical analysis of the Paris and Brussels conventions liability limit, Working Paper, Centre d'Analyse Economique, Universite Aix-Marseille, France.

Fiore, K. and Faure, M. (2006) The civil liability of European nuclear operators: which coverage for the New 2004 Protocol? Evidence from France, Working paper, Centre d'Analyse Economique, Aix-Marseille University, France.

Furse, M. (2006) Competition Law of the EC and UK, Oxford \& New York: Oxford University Press.

GAO (United States General Accounting Office) (2004) Nuclear Regulation - NRC's Liability Insurance Requirements for Nuclear Power Plants Owned by Limited Liability Companies, Report to Congressional Requesters 04-654, Washington, DC (May).

Havens III, C.W. and Theisen, R.M. (1986) 'The application of United States and ECC antitrust laws to reinsurance and insurance pooling arrangements', The Antitrust Bulletin: 1301.

Heyes, A. and Liston-Heyes, C. (1998) 'Subsidy to nuclear power through Price-Anderson liability limit: Comment', Contemporary Economic Policy 16: 122-124.

Heyes, A. and Liston-Heyes, C. (2000) 'An empirical analysis of the Nuclear Liability Act (1970) in Canada', Resource and Energy Economics 22: 91-101.

Holm, H.J. (1999) Aspects of information in risk-sharing, Working Paper, Lund University, Sweden.

IRSN (Institut de Radioprotection et de Sûreté Nucléaire)/EDF (Electricité de France) (1990) Etudes probabilistes de sûreté en France. Quelle probabilité de fusion du cœur des REP?, Journées SFEN, 16 May.

Kunreuther, H. (1997) 'Rethinking society's management of catastrophic risks', The Geneva papers on Risk and Insurance - Issues and Practice 83: 151-177.

Levie, G. and Cousy, H. (eds) (1994) La politique Européenne de concurrence en matière d'assurance, Brussels: Bruylant.

Lintner, J. (1965) 'The valuation of risk assets and the selection of risky investments in stock portfolios and capital budgets', Review of Economics and Statistics 47: 13-37.

De Loustal, B. (2003) Présentation d'Assuratome, Journée Benfield, 14 May, Paris.

Michel-Kerjan, E. and Marcellis-Warin, N. (2006) 'Public-private programs for covering extreme events: The impacts of information distribution and risk sharing', Asia-Pacific Journal of Risk and Insurance 1(2): $21-49$.

Markowitz, H.M. (1952) 'Portfolio selection', Journal of Finance 7: 77-91.

Markowitz, H.M. (1959) Portfolio Selection: Efficient Diversification of Investments, New York: Wiley \& Sons.

Muller, W. (1985) The Role of Insurance Industry in Covering Nuclear Third Party Liability Risks, Nuclear Third Party Liability and Insurance, Munich Symposium, Status and Prospects, Paris, OECD.

NEA/OECD (1994) Power Generation Choices: Costs, Risks and Externalities, Paris: OECD. 
Pelzer, N. (2007) 'International pooling of operators' funds: An option to increase the amount of financial security to cover nuclear liability?', Nuclear Law Bulletin 79: 37-55.

Prévot, H., de Juvigny, B., Louvot, M., Izart, C. and Lehmann, F. (2004) Les coûts complets du nucléaire et hypothèses de financement, Annexe 5 du Rapport d'enquête sur les prix de l'électricité, Conseil Général des Mines.

Rabin, R.L. and Bratis, S.A. (2006) 'United States', in M. Faure and T. Hartlief (eds) Financial Compensation for Victims of Catastrophes, Vienna: Springer, pp. 344-410.

Radetzki, M. and Radetzki, M. (2000) 'Private arrangements to cover large skill liabilities caused by nuclear and other industrial catastrophes', The Geneva Papers on Risk and Insurance - Issues and Practice 25: 180-195.

Reitsma, S.M.S. (1992) Nuclear Insurance Pools: History and Development, report presented to the OECD Symposium on Nuclear Accidents - Liabilities and Warranties, September, Helsinki, Finland.

Schieber, C. and Schneider, T. (2002) Valorisation monétaire des impacts sanitaires et environnementaux dun accident nucléaire. Synthèse des études externes, intérêts et limites de développements complémentaires, rapport $n^{\circ} 275$, CEPN, Paris.

Sharpe, W.F. (1964) 'Capital asset prices: A theory of market equilibrium under conditions of risk', Journal of Finance 19: 425-442.

Shavell, S. (1980) 'Strict liability versus negligence', Journal of Legal Studies 9: 1-25.

Shavell, S. (1987) Economic Analysis of Accident Law, Cambridge, MA: Harvard University Press.

Skogh, G. (1999) 'Risk-sharing institutions for unpredictable losses', Journal of Theoretical and Institutional Economics 55: 505-515.

Skogh, G. (2007) A European nuclear accident pool. A proposal based on the restated diversification theorem, Working paper, paper presented at the Joint Conference of the European Association for Law and Economics (EALE) and The Geneva Association for the Study of Risk and Insurance, Lecce, 15-16 June.

Smith, R.E., Canelo, E.A. and Di Dio, A. (1997) 'Reinventing reinsurance using the capital markets', The Geneva Papers on Risk and Insurance - Issues and Practice 82: 26-37.

Spadaro, J.V. and Rabl, A. (1998) External Costs of Energy: Application of the Externe Methodology in France, Final report (January).

Trebilcock, M. and Winter, R.A. (1997) 'The economics of nuclear accident law', International Review of Law \& Economics 17: 215-243.

Treynor, J.L. (1961) 'Toward a theory of market value of risky assets', published in 1999 in R.A. Korajczyk (ed) Asset Pricing and Portfolio Performance: Models, Strategy and Performance Metrics, London: Risk Books, pp. 15-22.

Treynor, J.L. (1962) Market Value, Time, and Risk, Mimeo.

Tyran, J.R. and Zweifel, P. (1993) 'Environmental risk internalisation through capital markets (Ericam): The case of nuclear power', International Review of Law and Economics 13: 431-444.

U.S. Congress Joint Committee on Atomic Energy (1974) 'Testimony before the atomic safety and licensing board, licensing hearing for Three Miles Island nuclear power plant by H. Denenberg', in U.S. Congress Joint Committee on Atomic Energy (ed) Possible Modification or Extension of the Price-Anderson Insurance and Indemnity Act, Washington, DC: U.S. Government Printing Office, pp. 226-240.

Vilnet, F. (2004) Réaction des marchés d'assurance et de réassurance et solutions de marché, Working paper, IDDRI, Paris.

Wagner, F. (1998) 'Risk securitization. An alternative risk transfer of insurance companies', The Geneva Papers on Risk and Insurance - Issues and Practice 89(October): 574-607.

Wang, H. (2007) 'Shifts in governance in the international regime of marine oil pollution compensation: A legal history perspective', in M. Faure and A. Verheij (eds) Shifts in Compensation for Environmental Damage, Vol. 21, Vienna: Springer, pp. 197-241.

Wu, H. and Skogh, G. (2005) 'The diversification theorem restated: Risk-pooling without assignment of probabilities', Journal of Risk and Uncertainty 31: 35-51.

Zech, J. (1998) 'Will the international insurance market replace traditional insurance products?', The Geneva Papers on Risk and Insurance - Issues and Practice 89(October): 490-495. 


\section{Appendix A}

$$
\begin{aligned}
P & =E(x)=\left(x \cdot p_{i} \cdot p_{1}^{\prime}\right) \cdot n+\left(x \cdot p_{i} \cdot p_{2}^{\prime}\right) \cdot n \\
& =\left(31 \cdot p_{i} \cdot 0.81\right) \cdot 58+\left(31 \cdot p_{i} \cdot 0.19\right) \cdot 58
\end{aligned}
$$

$p=p_{i} \cdot p_{j}^{\prime}$ being the probability of an accident (with $p_{i}=10^{-5}$ the probability of reactor core melt), $p_{j}^{\prime}$ the conditional probability (of radioactive releases) (with $p^{\prime}{ }_{1}=0.81$ for minor accidents and $p_{2}^{\prime}=0.19$ for major accidents), $x=31$ the amount of damages covered by insurance and $n=58$, the number of EDF's reactors. ${ }^{71}$

\section{Appendix B}

This result is obtained with Eq. (A.1) modified as follows:

$$
P=\frac{(6.4 / 58) \cdot 10000}{31}=€ 37.3 \text { million per reactor per year }
$$

\section{Appendix C}

Applying the CAPM, the cost of capital funds $k$ (and of the reserves for self-insurance) equals:

$$
k=r_{f}+\beta \cdot\left(r_{m}-r_{f}\right)
$$

with $r_{f}, r_{m}$ and $\beta$ being the riskless interest rate, the market interest rate and the sensitivity coefficient (the "financial beta") of the capital funds respectively. For EDF, $r_{f}$ is between 4 and 4.5 per cent, the risk premium $\left(r_{m}-r_{f}\right)$ is between 4 and 5.5 per cent and $\beta$ is between 1.15 and $1.6 .^{72} k$ is an immobilization (i.e. an opportunity) cost. It can therefore be considered as a discount rate. Hence, the annual cost of EDF's reserves (€60 million) is obtained as follows:

$$
A=\left[60-\frac{60 \cdot(1-p . n)}{(1+k)^{40}}\right]+\left[\sum_{t=1}^{t=40} \frac{60 \cdot(p . n)}{(1+k)^{t}}\right]
$$

The first term expresses the fact that, in $t=1$, the operator sets aside the reserves and that in $t=40$, it takes back its $€ 60$ million (discounted over the period) if no accident occurs (with probability $1-p . n$ ). However, the second term expresses the expected cost of losing the reserves set aside in the event of an accident. $p=p_{i} \cdot p^{\prime}{ }_{j}$ and $n=58$.

\section{About the Authors}

Professor Michael G. Faure is academic director of the Maastricht European Institute for transnational legal research (METRO) and professor of Comparative and

\footnotetext{
${ }^{71}$ IRSN and EDF (1990); NEA and OECD (1994); Schieber and Schneider (2002).

${ }^{72}$ http://www.boursorama.com; Dimson et al. (2001); Prévot et al. (2004).
} 
International Environmental Law at the law faculty of Maastricht University since September 1991.

Karine Fiore is research assistant in law and economics at the Centre d'Analyse Economique, Paul Cézanne University, Aix-en-Provence, France. Her research focuses on the insurance of nuclear risk and the nuclear operators' civil liability, in case of an accident on their installations. 